\title{
Política, religión y democracia deliberativa Un análisis desde la teoría del discurso
}

\author{
Santiago Prono* \\ Consejo Nacional de Investigaciones Científicas y Técnicas, Conicet-Argentina \\ Universidad Nacional del Litoral, Santa Fe, Argentina
}

\section{RESUMEN}

El presente trabajo analiza el actual posicionamiento teórico de Jürgen Habermas en relación con su reconocimiento del importante lugar que ocupa la religión en el espacio público-político. La tesis a defender sostiene que, aun teniendo en cuenta los exigentes requisitos del discurso argumentativo, que garantizan el valor epistémico de las decisiones adoptadas conforme al procedimiento que la democracia deliberativa establece, dicho posicionamiento resulta compatible con los fundamentos filosóficos de esta teoría política. Para justificar esta tesis, además de analizar algunos planteos críticos y confrontarlos con las pretensiones de validez que se expresan en tales fundamentos, se señalan las implicancias teóricas del concepto de sociedad civil que sostiene el filósofo, cuyas asociaciones se desempeñan en el ámbito de las relaciones informales de aquel espacio público-político. Esto último permite mostrar de qué modo es posible implementar este reconocimiento de participación de ciudadanos religiosos en el marco conceptual de la política deliberativa.

Palabras clave

Habermas, postsecularismo, teoría del discurso, democracia deliberativa, sociedad civil

Politics, religion and deliberative democracy.

An analysis based on the discourse theory

\section{ABSTRACT}

The present work analyzes the current theoretical position of Jürgen Habermas with regard to his recognition of the important place religion occupies in the

* Doctor en Filosofía, Universidad de Buenos Aires. Investigador, Consejo Nacional de Investigaciones Científicas y Técnicas, Conicet-Argentina. Docente-investigador, Universidad Nacional del Litoral, Santa Fe, Argentina. Correo electrónico: santiagoprono@hotmail.com. 
public-political space. The thesis to be defended affirms that, even taking into account the exigent requirements of argumentative discourse that ensure the epistemic value of the decisions adopted according to the process that deliberative democracy provides, such positioning is compatible with the philosophical grounds of this political theory. To justify this thesis, in addition to analyzing some critical presentations and confronting them with the claims of validity expressed in such conclusions, the theoretical implications of the concept of civil society that the philosopher sustains, whose associations operate in the field of informal relationships of the public-political space, are also mentioned. The purpose of this last explanation is to show the manner in which this recognition of participation of religious citizens in the conceptual framework of deliberative politics can be implemented.

\section{Keywords}

Habermas, post-secularism, theory of discourse, deliberative democracy, civil society

\section{Introducción}

En los últimos tiempos se evidencia en el contexto de la filosofía política una marcada recuperación del interés por la relevancia pública de la religión. Cada vez son más los trabajos publicados que analizan desde diversas perspectivas la conexión que, en términos de aportes y contribuciones, se establece entre las religiones universales y la política. ${ }^{1}$ Son las categorías mismas de lo religioso y lo secular las que se reexaminan, reelaboran y replantean en relación con los correspondientes ordenamientos sociopolíticos. S. Benhabib (2012) se ha interesado en la importancia de los valores religiosos para la sociedad al analizar desde una perspectiva constitucional las implicancias políticas que tienen para los ciudadanos las decisiones de los Estados respecto, por ejemplo, de las costumbres de ciertos grupos religiosos. En palabras de la filósofa, esto evidencia un "retorno de la teología política" que determina el modo de conceptualizar el estado de derecho. ${ }^{2}$ Por su parte, West

1 En realidad, este reconocimiento acerca de la importancia de la religión en la política está ya en Kant cuando, en el prólogo de su escrito sobre El conflicto de las facultades, no solo señala que "la revelación es útil para completar la falta teórica de la pura fe racional", sino también que "la religión es una necesidad política importantísima" ([1794] 1963, pp. 14, 16).

2 Así como Benhabib (2012), también Carl Schmitt, en su obra de 1922, Politische Theologie. Vier Kapitel zur Lehre von der Souveränität, afirmaba entonces que todos los conceptos sobresalientes de la moderna 
reflexiona acerca del futuro de la civilización capitalista desde el punto de vista de la religión (West, 2011), y mientras que Kramnick y Moore (2005) realizan una defensa moral del Estado secular, y Boston (2003) se pregunta por qué el derecho de las religiones está equivocado acerca de la separación de la Iglesia y el Estado, Lynn (2007) analiza el embate de la izquierda y la derecha contra la libertad religiosa buscando alcanzar un equilibrio entre religión y política. En este sentido, recientemente McGraw (2010), independientemente de las posturas extremas (i.e., defensores de regímenes teocráticos y defensores de la separación absoluta entre religión y política), también ha analizado la posibilidad de tomar distancia de las mismas, proponiendo un 'pluralismo estructural' como medio para conciliar a los creyentes con el proyecto liberal, en tanto que Bowman (2012) toma en consideración un concepto pragmático de religión al estudiar sus potenciales inherentes para la moralidad, la integración social y política, considerando un cosmopolitismo amplio.

En el caso de Habermas, desde hace ya tiempo este autor también se ha volcado hacia el estudio de temas relacionados con las influencias de las religiones en la esfera pública y sus aportes al estado democrático de derecho; se trata de una tematización que el filósofo pretende además articular con su teoría del discurso. Si bien Habermas lleva a cabo una reconstrucción de tipo histórico-hermenéutica respecto del importante lugar que de hecho ocupa la religión en el ordenamiento sociopolítico de las sociedades contemporáneas, al mismo tiempo atribuye también a lo religioso un sentido cognitivo en su relación con la política. Esto último parece plantear un interrogante acerca de la viabilidad conceptual de articular los campos de la religión y la política tal como sugiere el filósofo, y ello si se tienen en cuenta los exigentes requisitos del principio del discurso argumentativo, presupuesto por su teoría de la democracia deliberativa. En efecto, este principio, que es condición de validez de decisiones y normas (en este caso políticas) adoptadas mediante un procedimiento intersubjetivo de deliberación racional, establece que en el mismo solo tiene que tener vigencia la 'fuerza de coacción' que ejercen los mejores argumentos, excluyendo toda apelación a dogmas y demás creencias que pretendan ser reconocidas sin exponer las razones en que se basan, ni someterse a eventuales críticas. La teoría de la democracia deliberativa, en tanto que deliberativa, se caracteriza fundamentalmente por el resguardo y justificación del valor cognitivo de 
las decisiones adoptadas conforme al procedimiento que la misma establece (Elster, 1998). Es en función de este rasgo conceptualmente constitutivo de la teoría que se analiza aquí la viabilidad del actual reconocimiento habermasiano respecto de la religión en el ámbito de la esfera pública de la política democrática. Por ello, y frente a aquel interrogante de carácter crítico, la tesis que este trabajo se propone defender es que este posicionamiento del filósofo no entra en contradicción con los fundamentos de la democracia deliberativa, ni tampoco afecta la calidad epistémica de las decisiones que en función de ella se adoptan. Para fundamentar esta afirmación se proponen dos objetivos: analizar (algunas de) las objeciones que al respecto se plantean y confrontarlas con las pretensiones de validez en que tales fundamentos se expresan, y, sobre esta base, mostrar además también de qué modo es posible implementar conceptualmente este reconocimiento de participación de ciudadanos religiosos en el marco teórico de la política deliberativa.

La estructura expositiva de los argumentos propuesta para analizar este tema es la siguiente. Luego de una presentación general de la teoría de la democracia deliberativa de Habermas (1), se expone el actual posicionamiento del filósofo respecto de lo 'postsecular' y su correspondiente atribución a la fe de un carácter cognitivo (2). Esto permitirá analizar algunas objeciones que se plantean y exponer las razones por las cuales tal reconocimiento resulta compatible con esta teoría política (3). Seguidamente se explicita el sentido en que Habermas tematiza el concepto de sociedad civil, y ello a fin de mostrar de qué modo puede implementarse su actual pretensión de articular política y religión en el marco de la política deliberativa (4). A continuación de esta justificación, se propone una reflexión final acerca del sentido de plantear esta relación en un pensamiento posmetafísico que, al mismo tiempo, reconoce los caracteres distintivos de sociedades postseculares (5). El trabajo concluye con un breve señalamiento acerca de los resultados del análisis de este tema en la democracia deliberativa (6).

\section{Democracia deliberativa. Una introducción general}

La idea de democracia implica, a la vez, un concepto descriptivo y normativo. Es descriptivo porque da cuenta del modo en que se toman las decisiones en un Estado democrático, por ejemplo en el Parlamento, donde se discute sobre determinadas cuestiones; pero también, y fundamentalmente, es normativo porque exige que las decisiones del gobierno sean el resultado de la participación, directa o indirecta, de los ciudadanos como uno de los criterios de su legitimación política. Ahora bien, el concepto habermasiano de la democracia deliberativa también implica 
deliberación, intercambio de opiniones antitéticas que, al menos en principio, tendrían que confrontarse en términos de argumentos para intentar llegar a la mejor decisión posible y lograr acuerdos racionalmente motivados. Este concepto de política deliberativa expuesto por el autor (aunque no exclusivamente) en su principal obra filosófico-político-jurídica, Facticidad y validez (1992), ${ }^{3}$ comporta un carácter normativo y procedimental (pero también sustantivo), cuyo principio básico es el principio del discurso. Este principio, que ocupa un lugar central no solo en la teoría política, sino también en las teorías del derecho y de la moral de Habermas (y también de Apel), establece que las decisiones (en este caso) políticas son legítimas, y pueden ser reconocidas como tales en la medida en que se adopten mediante un procedimiento democrático de deliberación llevado a cabo en términos del intercambio público de razones en busca de un consenso: "válidas son solamente aquellas normas a las que todos los posibles involucrados puedan dar su asentimiento como participantes en discursos racionales" (Habermas, 1994, p. 138). Habermas concibe este principio como un examen crítico-argumentativo de los presupuestos inherentes a una afirmación determinada (Habermas, 1971). ${ }^{4}$ Se trata, pues, de un modelo de toma de decisiones y su correspondiente justificación (legitimación) intersubjetiva, que por principio se opone a toda pretensión de imponer dogmáticamente determinadas posturas sin exponer los fundamentos en los que se basa.

En relación con el punto de vista normativo, la democracia deliberativa no se limita a describir cómo es la realidad, o cómo se toman efectivamente las decisiones (aunque esto es algo que sin duda tiene en cuenta), sino que con base en su carácter reconstructivo, que explicita los presupuestos del discurso argumentativo mediante el análisis de la dimensión pragmática del lenguaje, esta teoría señala (o descubre) las presuposiciones normativas que hay que tener en cuenta como criterio de posibilidad y de validez de tales decisiones políticas adoptadas en contextos democráticos. La política deliberativa se basa en las reglas del discurso y formas de argumentación que toman su contenido normativo de la base de validez de la acción orientada al

3 Si bien esta obra apareció por primera vez en ese año, aquí se tendrá en cuenta la cuarta edición alemana publicada por Suhrkamp en 1994, que el autor presenta con una revisada y ampliada bibliografía.

4 Estos presupuestos se expresan en lo que el filósofo denomina como 'pretensiones universales de validez' (i.e. pretensiones de verdad, de rectitud normativa y de veracidad), y que estarían presentes en toda afirmación con sentido, aunque por supuesto siempre es una la que tiene preeminencia de acuerdo al tema de que se trate. Esto ha permitido ampliar el concepto mismo de validez que, conforme a los presupuestos del solipsismo metódico propio de la filosofía de la conciencia (que es el paradigma de la filosofía moderna), se lo concebía exclusivamente con relación a la representación semántico-referencial de estados de cosas, y situar el problema en el terreno de la dimensión pragmática del lenguaje, o de la comunicación y del discurso (Habermas, [1976] 1997; De Zan, 1993). 
entendimiento (y en última instancia de la estructura de la comunicación lingüística), que son reconstruidas por la pragmática universal del lenguaje:

Es pues en nuestro contexto de intereses que con estas consideraciones del proceso democrático se establecen también los criterios o puntos de referencia (die Weichen) para una conceptualización normativa del Estado y la sociedad [...] que se basa, en última instancia, en la estructura de la comunicación lingüística y en el orden no sustituible de la socialización comunicativa. (Habermas, 1994, pp. 359-360)

Sobre la base de este análisis de tipo reconstructivo, que permite explicitar o descubrir la racionalidad inmanente a la interacción social, Habermas pretende combinar el punto de vista universal y el sociohistórico en su teoría política. En efecto, el filósofo refiere a una razón 'históricamente situada', que si bien rechaza los meros contextualismos que derivan en posturas relativistas, por otro lado también se niega a adoptar puntos de vista abstractos que se distancien excesivamente de la facticidad propia del mundo de la vida (Lebenswelt) (Habermas, 1994, [1981] 1995).

Precisamente es en este sentido que cabe analizar el actual posicionamiento habermasiano respecto de lo político y su pretensión de articularlo con lo religioso.

\section{Postsecuralismo habermasiano}

A diferencia de lo que planteaba en Facticidad y validez (1994), cuando hablaba de sociedades 'completamente secularizadas's y de una razón procedimental en el sentido de un pensamiento posmetafísico de fundamentación, lo cual significa que solo se admite la 'fuerza' de los mejores argumentos como condición de validez

5 El término 'secular' proviene de la expresión latina saeculare, y tradicionalmente se ha planteado para diferenciarse de la religión, ya que refiere a una preocupación por las cuestiones temporales, terrenas o mundanas, propias del hombre, en contraposición a aquellas relacionadas con lo que está 'arriba', en las 'alturas', y todo lo referido a lo 'espiritual' o 'divino', que es el lugar habitado por los 'seres celestiales', y por supuesto por 'Dios', en donde el tiempo es eterno o, mejor dicho, donde el tiempo no transcurre. Se trata, pues, de un término que expresa la idea según la cual (en la modernidad) la religión ya no se recluye al ámbito privado, sino que además se supera y/o elimina. Así, a la secularización en tanto que concepto se la entiende como un proceso de laicización que alude a la relación entre religión y sociedad, en la que aquella se convierte en una institución junto con otras y pierde su pretensión globalizante, lo que supone que la sociedad, gradualmente, asume todas las funciones seculares previamente desarrolladas por la fe. Es precisamente en relación a esta idea que aquí se analiza el actual posicionamiento habermasiano en torno a la política. Para un análisis del llamado 'paradigma de la secularización' y de los extensos debates generados en el marco de las ciencias sociales, véase, entre otros, Donoso-Maluf (2008), Miranda (2007). 
de las decisiones adoptadas (Habermas, 1994, [1974] 1988), en Entre naturalismo y religión (2005), y en especial en su trabajo recientemente publicado: Nachmetaphysisches Denken II. Aufsätze und Repliken (2012), para Habermas el problema de la concepción del Estado constitucional y democrático de derecho comporta la necesidad de un debate sobre cuestiones filosóficas fundamentales que ya no pueden responderse solamente con las explicaciones normativas de la teoría política. ${ }^{6}$ Se trata este de un debate en el cual también tienen que poder admitirse los argumentos religiosos. En este sentido, se reconoce ahora que hay presupuestos que subyacen al Estado democrático de derecho como trasfondo cultural, ligados a tradiciones confesionales que desde hace siglos vienen influenciando, y determinando, la cultura occidental.

Para Habermas, la expresión 'postsecular' implica un predicado sociológico que permite describir a las sociedades modernas como ligadas con la continua existencia de diversas orientaciones de valor cultural, las cuales incluyen grupos y tradiciones religiosos. Lo postsecular no cabe interpretarlo aquí en el sentido de lo que 'está después', o 'más allá' de lo secular, sino más bien como un concepto que alude al cambio en la conciencia que se da en una sociedad secular en donde la religión no ha desaparecido, pues en ella conviven creyentes y no creyentes, cuyas creencias expresan diversas formas de vida que tienen que ser respetadas, y de las cuales se puede aprender porque aportan recursos de sentido indispensables (Reigadas, 2011). Esto, señala el filósofo, se evidencia a partir de un análisis reconstructivo de tipo hermenéutico que permitiría dar cuenta de un procedimiento de 'traducción' a lenguaje filosófico de contenidos cristianos, y a partir del cual sería posible explicitar, y analizar, principios normativamente revestidos como 'responsabilidad', 'autonomía', o 'individualidad' y 'comunidad', entre otros (Habermas, [2005] 2006, pp. 116-117). Lo importante a tener en cuenta aquí, que no se encuentra (al menos) explícitamente planteado en Facticidad y validez, es que para el autor hay presupuestos que subyacen al estado de derecho como trasfondo cultural, ligados a tradiciones confesionales que desde hace siglos vienen influenciando, $\mathrm{y}$ determinando, la cultura occidental. ${ }^{7}$

6 Habermas se basa aquí en la pregunta que el jurista alemán Ernst-Wolfgang Böckenförde formulara a mediados de los años 60 del siglo pasado (‘`cómo es posible que el Estado secular se sustente sobre premisas normativas que él mismo no puede garantizar?’), y que tuvo en cuenta para su debate con el cardenal de la Iglesia católica J. Ratzinger, realizado el 19 de enero de 2004 en la Academia Católica de Múnich sobre el tema "Fundamentos prepolíticos del Estado democrático de derecho, desde las fuentes de la razón y de la fe". La idea es que al diseño institucional de los Estados democráticos de derecho contemporáneos, subyacen presupuestos de carácter normativo que pueden considerarse como plasmaciones seculares de valores religiosos (González, Lozano, Pérez, 2009). Este también parece ser el argumento de C. McCrudden, quien recientemente publicó un trabajo en el que sostiene que las tradiciones legales y católicas conforman un 
Ahora bien, independientemente de esta lectura empírico-descriptiva, susceptible de explicitación mediante dicho método reconstructivo, lo importante a tener en cuenta en el marco de este trabajo respecto del actual posicionamiento habermasiano sobre el tema, son las implicancias teóricas que el mismo tiene para la democracia deliberativa. La ya señalada relevancia de esta cuestión se plantea a partir de que Habermas tematiza la relación entre política y religión, atribuyéndole a esta última también un sentido cognitivo, y con el que pretende fundamentar la incorporación de la fe en el ámbito de las discusiones teóricas relativas a su concepción del Estado de derecho. Su argumento es el siguiente.

El Estado liberal establece un ethos cognitivo para todos los ciudadanos tendiente a regular su interacción social frente a determinados problemas, el cual se impone de manera desigual a ciudadanos seculares y religiosos (Habermas, [2005] 2006). Por esta razón es que, reconociendo un cambio en la conciencia religiosa que desde los tiempos de la Reforma y la Ilustración está signado por un esfuerzo de traducción epistémica de sus convicciones profundas, el filósofo cuestiona lo que denomina como la "superación autorreflexiva de un autoentendimiento de la modernidad exclusivo y endurecido en términos secularistas"; por este motivo es que Habermas plantea la exigencia de no "excluir el posible contenido cognitivo que en términos de contribuciones puedan realizar las manifestaciones religiosas" ([2005] 2006, p. 147). A su entender, esto implica la posibilidad de atribuir una actitud epistémica a los ciudadanos seculares, lo cual conlleva un "cercioramiento autocrítico de los límites de la razón secular", y en donde, en nombre de una ética democrática de la ciudadanía, "se exija razonablemente tanto a ciudadanos seculares como religiosos que recorran procesos de aprendizaje complementarios" (Habermas, [2005] 2006, pp. 147-148; cursivas mías). En su obra recientemente publicada, Nachmetaphysisches Denken II, Habermas (2012) señala que estos procesos de aprendizaje presuponen un debate en términos discursivos (diskursive Auseinandersetzung) entre ciudadanos seculares y religiosos que tiene en cuenta un sentido reflexivo acorde con una razón posmetafísicamente clarificada: en el marco de un "uso público de la razón los ciudadanos seculares y religiosos tienen que poder encontrarse a un mismo nivel (Augenhöhe)", y a resultas de lo cual "las

consenso solapado respecto de la idea de 'derechos humanos' (McCrudden, 2012; Küng, 1997, 2006; Küng y Kuschel, 2006). En tal sentido, un tema a analizar es el de la traducción de tales valores cristianos a principios normativos sobre los cuales (en parte) se erigen las instituciones de los poderes (político y judicial) del Estado. Sin embargo, y aun cuando ya se han planteado objeciones en este punto (Prono, 2013; Aguirre, 2012; Lafont, 2009), un adecuado abordaje del mismo requiere de un estudio complementario en el que intervengan además otras disciplinas humanísticas, como la historia, la sociología o la filología, entre otras. 
contribuciones fundamentales de un lado para el proceso democrático [de toma de decisiones] son no menos relevantes que las del otro" (Habermas, 2012, p. 254). ${ }^{8}$

Esta interacción entre ciudadanos religiosos y seculares señalada por Habermas en su actual tematización de lo político, atribuye presuposiciones cognitivas a ambas partes como resultado de un proceso de aprendizaje complementario que presupone la "reciprocidad de reconocimiento", e incluso la posibilidad de "adoptar una perspectiva [en el sentido de un] intercambio de argumentos y opiniones" entre ambos tipos de ciudadanos (Habermas, 2012, pp. 156-157, 326).

\section{Política, religión y democracia deliberativa}

Llegados a este punto cabría preguntarse si este reconocimiento del importante lugar que Habermas asigna a la religión en el ámbito sociopolítico no contradice los presupuestos que subyacen a la estructura teórica de la democracia deliberativa. ${ }^{9}$

La respuesta a este cuestionamiento es negativa. En lo que respecta al espacio público-político, sin duda puede haber fricciones entre ciudadanos religiosos y seculares, y también que las creencias religiosas no siempre resulten discursivamente maleables. Este es el argumento de algunos críticos de este posicionamiento habermasiano. López de Lizaga, por ejemplo, sostiene que Habermas no tiene en cuenta las tensiones "que se producirían en la propia esfera pública entre los ciudadanos seculares y los ciudadanos religiosos si se exonerase a estos últimos de la exigencia para que traduzcan sus convicciones a los términos de la razón pública" (2011, pp. 17-18). Sin embargo, Habermas en ningún momento plantea tal exoneración pues, y de acuerdo con el carácter claramente normativo con que él mismo impregna su

8 En esta misma línea argumentativa, J. Chaplin ha señalado también la necesidad de reconocer la fuerza del argumento de la integración cognitiva que representa la religión, al afirmar que "muchos ciudadanos religiosos tienen a su disposición numerosos argumentos racionales acerca de la justificación de las leyes que evidentemente no dependen de una idea de Dios ni de la autoridad religiosa" (2012, p. 8; Habermas, [2005] 2006, pp. 119; 2012, p. 118).

9 Según algunos planteos críticos formulados desde el punto de vista de los ciudadanos religiosos, la teoría de la democracia deliberativa, basada en el concepto de racionalidad comunicativa, dificulta la adecuada tematización de la relación en cuestión porque desconoce características constitutivas fundamentales de las religiones, ignorando por ejemplo "el tipo de acción innovativa, que para la teología adopta un lugar central al posibilitar las relaciones mutuas y renovar los desgastados fundamentos de la intersubjetividad (ejemplos de esto son las nociones de 'perdón', 'perseverancia', luego de desilusiones, 'generosidad', etc.)”, con lo cual Habermas "no tendría en cuenta adecuadamente la motivación individual” (Junker-Kenny, 2011, pp. 36-37). En este sentido también se afirma que la pretensión habermasiana de articular política y religión es inviable porque implica un abandono de la tradición cristiana (Adams, 2006, p. 21). 
teoría política, establece que las comunidades religiosas, aun cuando en los debates públicos "puedan utilizar un lenguaje religioso" (Habermas, [2005] 2006, p. 109), tienen que "evitar el dogmatismo y las restricciones a la conciencia", lo cual expresa las consecuencias normativas de que "en la conciencia pública de una sociedad postsecular se siguen para las relaciones políticas entre ciudadanos no creyentes y ciudadanos creyentes" (Habermas, [2005] 2006, pp. 115-116). Por cierto que se da la posibilidad a las comunidades religiosas para que, en este ámbito de la opinión pública, ejerzan influencia sobre la sociedad en su conjunto, pero se trata de una posibilidad que se enmarca en el contexto de una expectativa normativa con la que el Estado liberal confronta a los ciudadanos religiosos y seculares, y por la cual las religiones "tienen que transformarse en lenguaje argumentativo y desprenderse de su contenido de verdad profana" (Habermas, [2005] 2006, p. 14). A los ciudadanos religiosos (junto con los ciudadanos seculares), sabemos, se les 'exige razonablemente' que 'recorran procesos de aprendizaje complementarios en términos discursivos'. No hay modo, entonces, de que se acepten creencias o prácticas religiosas que, por ejemplo, vulneren algunos de los derechos fundamentales del Estado liberal democrático. El reconocimiento de estas condiciones constituye un criterio a base del cual se pueden incluir (o se tienen que excluir) los argumentos de los ciudadanos religiosos para que puedan (o no) participar en este espacio público-político.

Si bien C. Lafont (2013) acepta la relación política-religión, también objeta el actual posicionamiento habermasiano en torno a lo político. Esta autora señala que dicho posicionamiento resulta inviable porque,

o bien colapsa la neutralidad del Estado al permitir participar a los ciudadanos religiosos en la esfera público-política, o bien se promueve que participen en estos espacios, pero a costa de que se comprometan con una forma de pensar enteramente diferente de sus convicciones religiosas. (Lafont, 2013, p. 6)

Sin embargo, y con respecto al primer problema, el cual se ubica en la misma línea que la objeción planteada por López de Lizaga, el actual planteamiento habermasiano sobre el tema no resulta inviable ya que para el filósofo alemán, y como la misma autora propone, en la esfera público-informal todos los ciudadanos (incluidos los religiosos) pueden apelar a cualquier razón en la que sinceramente crean, siempre que puedan mostrar, contra cualquier objeción en contrario, que las políticas que esas razones favorecen resultan compatibles, no solo con el compromiso democrático de tratar a todos los ciudadanos como libres e iguales, sino 
también, podría decirse, con un mínimo de racionalidad comunicativa, ${ }^{10}$ lo cual significa que ellas pueden ser razonablemente aceptadas por cualquiera:

la formación de la opinión y la voluntad en el espacio público democrático sólo puede funcionar, si un número suficientemente grande de ciudadanos cumple determinadas expectativas relativas a un comportamiento cívico que allane también ciertas diferencias profundas [en lo que respecta] a las creencias religiosas y a las cosmovisiones del mundo. Pero los ciudadanos religiosos sólo pueden afrontar estas expectativas en el supuesto de que cumplan de hecho determinadas condiciones cognitivas imprescindibles. Deben haber aprendido a poner las convicciones de su propia fe en una relación reflexiva y lúcida con el hecho del pluralismo de religiones y cosmovisiones, y deben haber armonizado su fe con el privilegio epistemológico de las ciencias socialmente institucionalizadas, con el primado del Estado laico, y con la moral universalista de la sociedad. (Habermas, [2005] 2006, p. 12)

En el debate público, las razones que los ciudadanos religiosos (y no religiosos) plantean, tienen que poder mostrar que son consistentes con el reconocimiento de estas condiciones. Es sobre esta base que es posible garantizar una deliberación democrática que implique una esfera pública completamente inclusiva, en la que se reconozca a todos los ciudadanos (incluidos los religiosos) el derecho a participar en democracia como libres e iguales para plantear sus razones públicamente reconocibles como tales (sean o no religiosas), lo cual no significa que por ello se acepten.

Con relación al segundo problema señalado por Lafont, tampoco corresponde la atribución de tal inviabilidad conceptual, toda vez que la necesidad de que los ciudadanos religiosos (en colaboración con los ciudadanos seculares) expresen sus creencias en forma de argumentos públicamente comprensibles, y dejen de lado sus convicciones cuando no resulten compatibles con el reconocimiento de los requisitos deliberativos, constituye una exigencia que se justifica en razón de que la misma contribuye a resguardar la calidad epistémica de las decisiones adoptadas conforme al procedimiento intersubjetivo de deliberación que la política delibera-

10 Tal como explicita en su teoría de la acción social, para Habermas un uso 'comunicativo' de la racionalidad tiene lugar cuando los planes de acción que ella representa no dependen de un cálculo egocéntrico de utilidades, sino de la coordinación de actos de entendimiento. Se trata de una relación comunicativa en el mundo social orientada al entendimiento intersubjetivo y a la formación de un consenso racionalmente motivado considerado como válido por los interlocutores involucrados, que hace posible la coordinación no forzada de sus respectivos planes de acción (Habermas, [1981] 1995). 
tiva establece. La participación y posibles aportes provenientes desde el punto de vista de la fe tienen que satisfacer esta exigencia como requisito ineludible para el sostenimiento conceptual de las pretensiones de validez de esta teoría política, y de las decisiones del estado democrático de derecho que conforme a ellas se adopten. Se trata, pues, de una condición que habilita la posibilidad (y acaso necesidad) de que los ámbitos o instituciones formales del Estado, que son los que deciden las políticas colectivamente vinculantes, puedan nutrirse de los aportes y contribuciones que se planteen en (o provengan de) la esfera de la opinión pública democrática. ${ }^{11}$ Promover e incentivar, con estas condiciones señaladas, la inclusión en la esfera pública de la política de todos los ciudadanos (incluidos los religiosos) constituye un requerimiento ineludible que no solo permite asegurar el valor epistémico de las decisiones adoptadas, sino que también, y fundamentalmente, contribuye a consolidar su legitimidad democrática.

También se plantean objeciones a la pretensión habermasiana de articular estos espacios público-políticos con los ámbitos formales y decisorios de los poderes políticos del Estado. En efecto, se afirma que Habermas "no se hace cargo de las tensiones que aparecen cuando se intenta mantener el laicismo del Estado y al mismo tiempo se rechaza para la esfera pública el principio de justificación secular" (López de Lizaga, 2011, p. 18). Sin embargo, para aquellos espacios formales de toma de decisiones, las exigencias normativas que plantea Habermas son aún más fuertes. Ya en Entre naturalismo y religión el filósofo señala explícitamente que el Estado tiene que esperar que se reconozca el principio según el cual el ejercicio legítimo de la dominación "se ejerce con neutralidad respecto de las diversas cosmovisiones del mundo", y también afirma que para esto "sólo cuentan razones seculares", no religiosas (Habermas, [2005] 2006, p. 137). El actual reconocimiento del autor respecto del importante lugar de la religión en la esfera de lo político no afecta los fundamentos teóricos de la democracia deliberativa, pues el filósofo diferencia entre el ámbito postsecular, que es en donde se expresan las manifestaciones (y posibles contribuciones) religiosas, y el secular, en el que las instituciones del Estado tienen que decidir mediante el principio del discurso:

Todo ciudadano tiene que saber y aceptar que sólo cuentan las razones seculares más allá del umbral institucional que separa a la esfera pública informal de los parlamentos, los tribunales, los ministerios, y las administraciones, [pues] "los umbrales instituciones entre la esfera público-política 'espontánea' y los procederes formales de las corpo-

11 En la próxima sección se analiza este tema. 
raciones estatales [...] constituyen filtros que, de entre la maraña de voces [...] de la comunicación pública, únicamente dejan que pasen las contribuciones seculares. (Habermas, [2005] 2006, pp. 137, 139)

Y en el mismo sentido se expresa el filósofo en su reciente obra antes citada, en donde también se refiere a

un filtro institucional entre la comunicación informal en el espacio público y las discusiones formales que guían las decisiones colectivamente vinculantes, el cual tiene que asegurar que todas las decisiones estatales sancionadas puedan formularse y justificarse en un lenguaje generalmente comprensible. (Habermas, 2012, p. 301)

La idea aquí, como en aquella obra de 2006, es que "la separación (Trennung) entre Estado e Iglesia necesita de un filtro entre estas dos esferas, a través del cual sólo pueden atravesar hacia la agenda de las instituciones estatales las contribuciones seculares [...] del espacio público (Öffentlichkeit)" (Habermas, 2012, pp. 326-327).

La relación entre el ámbito secular y postsecular está mediada entones por una instancia que solo deja pasar los aportes racionalmente fundamentados de acuerdo con el principio del discurso, y en el marco del cual, sabemos, los interlocutores involucrados acuerdan guiarse por la "fuerza de coacción" que solo ejercen los mejores argumentos; de hecho, en la introducción de Nachmetaphysisches Denken II sostiene Habermas que no puede "fundamentar la recomendación [de un] modo de 'pensamiento postmetafísico' para filosofar, sin al mismo tiempo promover la comprensión de un concepto de 'razón comunicativa'” (Habermas, 2012, p. 8).

El actual reconocimiento habermasiano respecto del importante lugar asignado a la religión en el ámbito político, no entra pues en contradicción con el marco teórico de su concepción de la democracia deliberativa, ni afecta el valor epistémico de las decisiones adoptadas conforme al procedimiento que la misma establece. Se trata, así, de una rehabilitación de la religión que, sin embargo, se plantea dentro de los límites de un pensamiento posmetafísico, que no renuncia a las pretensiones de validez de la teoría del discurso como trasfondo conceptual sobre el cual se apoya la concepción habermasiana de la democracia deliberativa.

Ahora bien, si tal reconocimiento resulta compatible con los fundamentos teóricos de la política deliberativa (Pizzi, 2001; De Zan, 2001; Reigadas, 2011), la pregunta que aun así entonces cabe formular es ¿cómo, precisamente, es posible implementar esta articulación entre lo secular y lo postsecular, entre la razón y la fe, en el marco conceptual de la democracia deliberativa? 
A fin de dar respuesta a este interrogante, es necesario situar ahora el análisis de esta relación entre política y religión en el nivel en que el filósofo la plantea, que es el nivel informal de la interacción social dado por el espacio de la opinión pública-política, en donde se expresa su concepto de 'sociedad civil'. Esto contribuye a reforzar la justificación de la tesis propuesta, a la vez que ofrece un primer paso hacia la comprensión de la pretensión habermasiana consistente en intentar fundamentar tal clase de articulación.

\section{Opinión pública y sociedad civil}

Habermas concibe las organizaciones de la sociedad civil (OSC) como parte del espacio público-político, en donde interactúan de manera informal los diversos actores de la sociedad. Se trata de organizaciones y movimientos de formación más o menos espontáneas que no pretenden tomar el poder del Estado, pero que en ocasiones están en conflicto con este, y plantean problemas a sus instituciones políticas formales en busca de interpretaciones públicas para sus intereses comunes, por ejemplo movilizándose y ejerciendo presión para su reconocimiento por parte de aquellos ámbitos decisorios. Se trata, pues, de un modo de concebir la sociedad civil en el sentido de que esta adopta un importante lugar en el ordenamiento político, el cual tiene que permanecer permeable a las demandas y los aportes que desde ella surjan. Habermas define el concepto de sociedad civil en los siguientes términos:

La sociedad civil se basa en esas asociaciones, organizaciones y movimientos surgidos de manera más o menos espontánea que toman la resonancia que los problemas sociales encuentran en los asuntos de la vida privada, condensándolos y elevándoles la voz, transmitiéndolos al espacio de la opinión pública política. [...] Tal base asociativa [...] constituye el substrato de ese público general de ciudadanos que emerge de la esfera privada y busca interpretaciones públicas para sus intereses sociales y experiencias, y ejerciendo influencia sobre la formación de la opinión y la voluntad [política] institucionalizada. (Habermas, 1994, pp. 443-444).

Si bien son los sectores de la sociedad civil los que explicitan y descubren problemas, 'poniéndolos sobre la mesa y levantando el volumen' de las correspondientes demandas para que sean resueltas, las decisiones para ello se toman y justifican en el marco de las instituciones del Estado. 
Esta teoría política reafirma así una concepción del estado de derecho, en donde las opiniones y las iniciativas ciudadanas de la sociedad civil se tienen que canalizar a través de los correspondientes órganos institucionales del Estado. Al mismo tiempo se reconoce también el lugar central del proceso de formación de la opinión y voluntad políticas llevado a cabo en términos intersubjetivos en estos espacios público-políticos informales, y ello de un modo que trasciende los límites que determinan los intereses particulares de las OSC: "El núcleo de la sociedad civil forma una conciencia asociativa (Assoziationswessen) que institucionaliza discursos de solución de problemas para preguntas de intereses generales en contextos de opinión pública organizada" (Habermas, 1994, pp. 443-444). En este sentido cabe destacar también el reconocimiento habermasiano de los positivos resultados de las influencias y demandas de las OSC para el mejoramiento (expresado incluso en términos de revolución) del ordenamiento sociopolítico, y que el filósofo explicitara en el prefacio de la nueva edición alemana de 1990 de Strukturwandel der Öffentlichkeit:

La coyuntura del concepto de sociedad civil se ha planteado [como] crítica, ante todo por los disidentes de las sociedades de socialismo de estado contra la aniquilación (Vernichtung) totalitaria del espacio público político. [Y sobre esto] ha jugado un importante rol el [abordaje] teórico-comunicativo del concepto de totalitarismo de H. Arendt. [...] Los cambios revolucionarios de Europa centro-oriental han confirmado este análisis [...] como si se tratara de un experimento socio-económico a gran escala, [...] de cómo el aparato de dominación fue ciertamente revolucionado a través de los pacíficos y operantes movimientos sociales. (Habermas, [1968] 1990a, p. 47) ${ }^{12}$

En la democracia deliberativa se evidencia, según Habermas, entonces, una interacción entre 'el centro' y 'la periferia', entre las deliberaciones y las decisiones institucionalizadas, y las opiniones desarrolladas informalmente en los espacios públicos. Esto permite dar cuenta de que si bien esta teoría política mantiene (como

12 Cuando Habermas (1994) analiza "El papel de la sociedad civil y de la opinión pública" en el cap. VIII de Facticidad y validez, señala que "cuando se encuentran juntos los actores de la sociedad civil [...] sus iniciativas pueden tener éxito porque con la movilización endógena del espacio público (Öffentlichkeit) toma fuerza una ley que de otro modo permanece latente, a saber, $[\ldots]$ que los actores en la arena deben su influencia al asentimiento de [quienes ocupan] la galería" (Habermas, 1994, pp. 461-462). En este sentido, B. Peters también ha seńalado que si bien la política y el derecho pueden considerarse como campos o ámbitos institucionales compuestos por los órganos parlamentario, ejecutivo y judicial, "la legitimidad de las decisiones es dependiente del proceso de formación de la opinión y la voluntad [generado] en la periferia" (Peters, [1994] 2007, p. 44, ver también p. 36). 
el liberalismo) la separación Estado-ciudadanos en lo que respecta a la toma de decisiones colectivamente vinculantes, las cuales solo se adoptan en el contexto de las instituciones formales y constitucionalmente reconocidas del Estado (Ejecutivo y Legislativo), de todos modos se tienen en cuenta las exigencias, y también los aportes y contribuciones provenientes de aquella periferia.

A partir de esta interpretación de las características fundamentales del concepto habermasiano de sociedad civil, la respuesta a la pregunta planteada al final de la sección anterior ('¿cómo puede implementarse en la democracia deliberativa esta articulación entre política y religión que plantea el filósofo?'), es que en el marco teórico de la política deliberativa la importancia otorgada a los aportes y contribuciones de los ciudadanos religiosos se justifica teniendo en cuenta el tipo de interacción que Habermas establece entre, por un lado, los espacios informales de la opinión pública y de las OSC que en ella se enmarcan, y, por el otro, la estructura formal y decisoria del Estado. Esta es la base conceptual que es posible identificar como punto de apoyo del actual reconocimiento habermasiano respecto de la importancia, no solo entonces de los eventuales aportes que (en términos del seńalamiento de problemas y/o propuestas de solución) puedan realizar las OSC para el mejoramiento del desempeño institucional del estado de derecho, sino también de aquellos (aportes y/o señalamientos) que puedan provenir de las religiones, las cuales también se desempeñan en el ámbito público-político. La idea aquí es que

la presión de las opiniones públicas [de la sociedad civil, y en las que se incluyen las religiones,] obliga a un modo extraordinario de elaboración de los problemas [por]que redunda en beneficio de la regulación de la circulación del poder efectuado en términos de estado de derecho, es decir, [porque] actualiza sensibilidades para responsabilidades politicas reguladas por el derecho constitucional. (Habermas, 1994, p. 433; ver también 1994, p. 431; 2006, p. 138; 2012, pp. 326-327)

Por supuesto, esta separación entre espacios políticos formales e informales no implica un desconocimiento de los posibles aportes que puedan realizar los ciudadanos religiosos, como afirman algunos planteamientos críticos al poner énfasis exclusivamente en la cuestión del 'filtro' que Habermas 'ubica' en el umbral de entrada de las instituciones políticas y decisorias del Estado, ${ }^{13}$ pues aun con los requisitos

13 Bader (2012) afirma que, debido a las restricciones que impone el actual posicionamiento habermasiano sobre este tema cualquier Estado liberal-democrático tiene que ser secular, y que por esto al final no se plantean demasiadas presiones sobre los ciudadanos seculares. Así, este autor propone reemplazar el término 'postsecular' por el de 'constitucionalismo liberal-democrático' (Bader, 2012). 
que a tales ciudadanos se imponen, estas instituciones, sabemos, tienen que resultar permeables a aquellas posibles contribuciones que ellos, ciudadanos religiosos (al igual que los seculares), puedan realizar en el ámbito de la opinión pública, lo cual expresa a su vez la pretensión habermasiana de relacionar la facticidad y la validez.

La reflexión sobre el concepto habermasiano de sociedad civil contribuye, pues, a explicitar de qué modo es posible articular conceptualmente política y religión en el marco teórico de la democracia deliberativa. Sin embargo, esto no es todo lo que puede decirse para comprender el planteo de tal pretensión en el contexto de un pensamiento posmetafísico como el que aún sostiene el autor.

\section{Postsecularismo y posmetafísica}

A pesar de las señaladas objeciones contra el actual posicionamiento habermasiano sobre el tema, Lafont también reconoce que los ciudadanos religiosos pueden participar del espacio público político, ya que, a su entender,

nadie tiene la obligación de comprometerse en una manera de pensar enteramente extraña a sus propias posturas cognitivas, ya sean religiosas o seculares, para participar seriamente en la deliberación pública acerca de políticas coercitivas con las cuales todos deberían comprometerse. (Lafont, 2009, p. 143)

Trabajos recientes sobre la filosofía del liberalismo político, por ejemplo en el caso de Rawls, sugieren que él mismo no adopta en realidad ninguna definición sobre la relación que debería (o no) establecerse entre política y religión, pues esta es, precisamente, una cuestión que hay que presuponer dado el hecho del pluralismo:

El liberalismo político [...] exhibe una estructura dualista: por un lado identifica amplias condiciones de legitimidad constitucional, [pero] por el otro [, y debido a las diferentes cosmovisiones existentes,] permite a un alto nivel de dependencia contextual indefiniciones políticas (political inconclusiveness), incluso acerca de principios de justicia. (Laborde, 2013, p. 79)

La idea aquí es que la separación y el establecimiento de la relación 'Estado-Iglesia' son igualmente defendibles, no como un fin en sí mismo, sino más bien porque ellos protegen o promueven ideales de justicia liberal. 
Ahora bien, en el caso de Habermas, e independientemente ya de la justificación de la tesis propuesta sobre la base del análisis tanto de las objeciones planteadas como así también del concepto de sociedad civil, ¿cuáles son las presuposiciones (o motivaciones) filosóficas en que él mismo se basa para fundamentar su posicionamiento sobre este tema?, ¿¿cuál es el sentido, por qué tal pretensión de relacionar política y religión?

En la actual concepción habermasiana de la política democrática, regida por los presupuestos normativos que resultan cognitivamente ineludibles de su teoría del discurso, las convicciones religiosas políticamente relevantes que puedan contribuir al mejoramiento del desempeño de las instituciones democráticas, se tienen en cuenta a partir de considerarlas como aportes provenientes de cosmovisiones distintas que cabe reconocer ( $\mathrm{y}$ no excluir):

El estado liberal no puede sostenerse en los meros fundamentos insensibles de acuerdos forzados. Como estado democrático de derecho él mismo depende de creencias de legitimación arraigadas, y para obtener esta legitimación tiene que fundamentarse en que en una sociedad pluralista los creyentes de diferentes religiones, y los no creyentes, tienen que poder llegar a aceptarse en igual medida. [Ciertamente que] La constitución del Estado no sólo ha de ser neutral frente a cosmovisiones, sino que también tiene que fundamentar este posicionamiento. [Sin embargo,] Y más allá de este requerimiento normativo, no puede permanecer sordo a las comunidades religiosas. Por esto aquí entra en juego un proceso de aprendizaje en el cual la parte secular y la religiosa se enredan mutuamente. (Habermas, 2008, pp. 32-33; ver también) ${ }^{14}$

14 En este sentido, diversos autores reconocen los aportes de la religión a la convivencia democrática. González (1997) admite el importante rol desempeñado por la Iglesia en Colombia en los procesos de paz; Arias y González (2006) han sostenido que la jerarquía católica colombiana se encuentra comprometida con la búsqueda de mecanismos que permitan superar definitivamente el conflicto. En opinión de Pińeiro, "la iglesia católica ayudó a construir una sociedad colonial en Latinoamérica mediante su labor [a la vez] evangelizadora y civilizadora, y más allá de las luces y sombras que [, qué duda cabe, ciertamente] se puedan encontrar, ha caminado junto a los pueblos latinoamericanos y los ha acompañado en todas las vicisitudes realizando no pocos aportes fundamentales" (2010). Y McConnell (1992) alega que la identidad religiosa sirve a un propósito público especial en las democracias orientadas por el mercado y por los medios, ya que ayuda a superar el individualismo agresivo que tanto amenaza el orden civil (McConnell, 1992). Como ejemplo de estas consideraciones, cabe destacar el importante rol que la Iglesia católica argentina, junto con directivos del Programa de las Naciones Unidas para el Desarrollo (PNUD), desempeńó en la crisis de este país de 2001-2002, contribuyendo a preservar la institucionalidad y reconstruir la paz social, y sentando las bases para comenzar a dar respuestas concretas a los principales problemas y demandas de la sociedad argentina. 
Es preciso, entonces, aceptar la participación en la esfera pública de las convicciones religiosas, ya que de otro modo se corre el riesgo de empobrecer la discusión en este ámbito, privando a la sociedad de los valiosos e indispensables recursos que aquellas representan, y que una sociedad secularizada por sí misma no puede proveer ni agotar (Habermas, 2006, 2012; Reigadas, 2011). ${ }^{15}$

A diferencia, por ejemplo de J. Rawls, cuya concepción de la razón pública pretende excluir todo planteo de intereses o cosmovisiones particulares que no puedan defenderse públicamente para fundamentar decisiones colectivamente vinculantes, Habermas reconoce la importancia de las contribuciones religiosas de ciudadanos postseculares al ámbito político. ${ }^{16} \mathrm{El}$ abordaje teórico respecto de la política que Habermas realiza en sus últimos escritos, y aquí es particularmente importante la introducción de Nachmetaphysisches Denken II, se opone tanto al ablandamiento (Aufweichung) de los derechos fundamentales, como así también (y acorde con la teoría crítica de sus maestros de la Escuela de Frankfurt) al fundamentalismo ilustrado (Aufklärungsfundamentalismus), que pretende una universalización excluyente de la razón, y según la cual lo que no se somete al cálculo lógico-matemático y a la observación como cánones de la filosofía positivista, cae fuera de toda posible noción de sentido. De este modo se reactualiza (de manera no neutral) una histórica pero incesante polémica de la filosofía de las ciencias sociales y humanas, que es la polémica entre el punto de vista de la explicación causal (Erklärung), basada en la experiencia, y el de la comprensión (Verständigung), en el sentido de una concepción metodológica propia de las ciencias humanas, o 'del espíritu' (en el sentido de W. Dilthey).

Lo que Habermas ha abandonado expresamente en sus escritos actuales sobre teoría política no es el pensamiento metafísico como tal, sino el fundamentalismo, que pretendía poder derivar sistemática y deductivamente de la metafísica como filosofía primera los principios fundantes de todos los otros campos del saber. Esta, si se quiere, 'desestructuración' de la forma sistemática de la filosofía, permite una nueva autocomprensión de su posición en el contexto del conjunto

15 Esta es precisamente la postura expresada por el filósofo en su discusión con el cardenal Ratzinger antes citada, y en la que debatieron sobre la posible capacidad de las religiones para proporcionar un fundamento a la democracia.

16 En efecto, esto constituye un punto de referencia opuesto al original planteamiento rawlsiano sobre el tema de la fe porque, al concebirla como una 'doctrina comprehensiva' (junto con las de tipo 'filosófico' o 'morales'), la excluye de los procedimientos decisorios debido a que comportan el tipo de creencias que dificultan la creación de todo posible consenso sobre temas de justicia básica que regulan el ordenamiento institucional del estado de derecho. Ver Rawls ([1971] 1999a, 1999b, 1999c, [1993] 2005). Para un análisis del ideal deliberativo de reciprocidad de Rawls, en el marco del cual se aborda este tema, véase también Garreta Leclerq (2009a, 2009b, 2012). 
de las ciencias y de la cultura. De lo que se trata entonces, en última instancia, es de mostrar una predisposición hacia la apertura al diálogo entre diferentes campos disciplinares, y de cómo el abandono del dogmatismo metafísico no trae aparejado el escepticismo ni la pérdida de solidez y firmeza de las convicciones más profundas (De Zan, 2001).

\section{Reflexiones finales}

Si además del análisis y la justificación del poder, la filosofía política aborda también el problema de la relación entre Estado y sociedad, entonces el hecho de que la separación entre cosmovisiones religiosas y seculares divida en igual medida la sociedad implica que este es, también, un asunto que concierne a la teoría política. En este marco, el análisis habermasiano del tema de la relación entre política y religión intenta superar esta lectura dicotómica, en el sentido de que la conciencia religiosa se torna reflexiva al tiempo que se opera una superación (también reflexiva) de la conciencia laica. Esto implica un doble proceso de aprendizaje complementario que pone de manifiesto una descripción que, como reconoce Habermas, aun así se lleva a cabo "desde la distanciada perspectiva de un observador postmetafísico" (Habermas, [2005] 2006, p. 14).

La pretensión habermasiana de relacionar política y religión en el marco teórico de la democracia deliberativa no entra, pues, en contradicción con los fundamentos filosóficos de esta teoría política. Esto resulta particularmente evidente teniendo en cuenta no solo el concepto de sociedad civil que dicha teoría comporta, sino también los exigentes requisitos discursivos que establece el referido 'filtro institucional', aunque sin por ello afectar la exigencia que recae sobre las instituciones estatales para que las mismas resulten 'permeables' a los aportes informales provenientes de la opinión pública: de este modo es posible comprender por qué es necesario sostener que los procedimientos de fundamentación de la democracia deliberativa comportan diversos niveles de comunicación, en los que también se incluyen las interacciones sociales informales de la opinión pública política, y de la que pueden formar parte los ciudadanos religiosos.

Como resultado del análisis precedente, cabe señalar que el actual posicionamiento habermasiano resulta coherente con el planteamiento teórico de la política deliberativa, no viéndose por lo tanto afectada la calidad epistémica de las decisiones adoptadas conforme al procedimiento decisorio que la misma establece. Por cierto, nada de esto debe entenderse en el sentido de pretender tributar elogios públicos al punto de vista de las religiones por sobre el de la razón, sino (en el sentido) de 
promover un diálogo, reflexivo y no necesaria mente irracional, entre ambas partes como medio para contribuir al desempeño de actitudes deseables en las relaciones entre las diversas organizaciones o grupos de estos espacios público-políticos y las instituciones democráticas del estado de derecho.

Recibido junio 18, 2014 Aceptado julio 31, 2014

\section{Referencias bibliográficas}

Adams, N. (2006). Habermas and Theology. Cambridge: Cambridge University Press.

Aguirre, J. (2012). Jürgen Habermas y la religión en la esfera pública. Ideas y Valores, Vol. LXI, N $148,59-78$.

Arias, R., González, F. (2006). Búsqueda de la paz y defensa del "orden cristiano": el episcopado ante los grandes debates de Colombia (1998-2005). En F. Buitrago (ed.), En la encrucijada: Colombia en el siglo XXI (pp. 173-206). Bogotá: Norma.

Atria, F. (2009). La verdad y lo político (II ). Democracia y ley natural. Persona y Sociedad, Vol. XXIV, No 2, 35-64.

Bader, V. (2012). Post-secularism or liberal-democratic liberalism? Erasmus Law Review, Vol. $5, \mathrm{~N}^{\circ} 1,1-22$.

Benhabib, S. (2012). The return of political theology: The scarf affair in comparative constitutional perspective in France, Germany and Turkey. Philosophy \& Social Criticism 36, 451-471.

Boston, R. (2003). Why the Religious Right Is Wrong About Separation of Church and State. Nueva York: Promotheus Books.

Bowman, J. (2012). Why cosmopolitanism in a post-secular age? Taylor and Habermas on European vs. American exceptionalism. Philosophy \& Social Criticism, Vol. 38, 127-147. Chaplin, J. (2012). Law, religion and public reasoning. Oxford Journal of Law and Religion (Enero), 1-21. Disponible en http://ojlr.oxfordjournals.org/reports/most-read [octubre 2013].

Cohen, J., Arato, A. (1992). Civil Society and Political Theory. Cambridge: MIT Press.

Contreras, S. (2010). Metafísica, naturaleza y orden moral. Persona y Sociedad, Vol. XXV, $\mathrm{N}^{\circ} 1,69-83$.

De Piero, S. (2005). Organizaciones de la sociedad civil. Tensiones de una agenda en construcción. Buenos Aires: Paidós.

De Zan, J. (1993). Libertad, poder y discurso. Buenos Aires: Almagesto.

(2001). La desestructuración del campo disciplinario de la filosofía. En D. Michelini et al. (eds.), Saber, poder, creer. Homenaje a Carlos Pérez Zavala (pp. 32-37). Río Cuarto: Ediciones del ICALA. 
(2006). Ciudadanía y sociedad civil. La democracia y los sujetos de la política. Erasmus. Revista para el Diálogo Intercultural, Año VII, Vol. 2, 119-162.

(2008). Introducción: La teoría tradicional y los nuevos sujetos políticos de la sociedad civil. En J. De Zan y F. Bahr (eds.), Los sujetos de lo politico en la filosofía moderna y contemporánea (pp. 17-54). Buenos Aires: UNSAM.

Dilthey, W. [1883] (1944). Introducción a las ciencias del espiritu. México D.F.: Fondo de Cultura Económica.

Donoso-Maluf, F. (2008). El porvenir de una desilusión: hacia un examen pluriaxial de la secularización. Teología y Vida, Vol. XLIX, 799-835.

Elster, J. (1998). Introduction. En J. Elster (ed.), Deliberative Democracy (pp. 1-18). New York: Cambridge University Press.

Garreta Leclerq, M. (2009a). Acerca de las dificultades para justificar el ideal deliberativo de reciprocidad. En M. Garreta Leclerq y J. Montero (eds.), Derechos humanos, justicia y democracia en un mundo transnacional (pp. 179-200). Buenos Aires: Prometeo.

(2009b). Democracia deliberativa y justificación mutua. Revista de Filosofía, Vol. $34, \mathrm{~N}^{\circ} 2,5-27$.

(2012). Liberalismo político y reciprocidad: justificación epistémica de creencias versus justificación moral de acciones. Isegoría, No 46, 279-294.

González, F. (1997). Poderes enfrentados, Iglesia y Estado en Colombia. Bogotá: Cinep.

González, E., Lozano, J., Pérez, J. (2009). Beyond the conflict: Religion in the public sphere and deliberative democracy. Res Publica. A Journal of Moral, Legal and Social Philosophy, Vol. 15, No 3, 251-267. Disponible en http://repositori.uji.es/xmlui/bitstream/handle/10234/23014/35506.pdf?sequence=1 [mayo 2014].

Habermas, J. (1971). Theorie und Praxis. Frankfurt: Suhrkamp.

[1974] (1988). La lógica de las ciencias sociales. Madrid: Tecnos.

[1968] (1990a). Strukturwandel der Öffentlichkeit. Frankfurt: Suhrkamp.

(1990b). Pensamiento postmetafisico. Madrid: Taurus.

(1991). Texte und Kontexte. Frankfurt: Suhrkamp.

(1994). Faktizität und Geltung. Beiträge zur Diskurstheorie des Rechts und des demokratischen Rechtsstaats. Frankfurt: Suhrkamp.

[1981] (1995). Theorie des kommunikativen Handelns (I: Handlungsrationalität und gesellschaftliche Rationalisierung). Frankfurt: Suhrkamp.

[1976] (1997). ¿Qué significa pragmática universal? En J. Habermas, Teoría de la acción comunicativa. Complementos y estudios previos (pp. 299-368). Madrid: Cátedra.

(1999a). La inclusión del otro. Barcelona: Paidós.

(1999b). Wahrheit und Rechtfertigung. Frankfurt: Suhrkamp.

(1999c). Fragmentos filosófico-teológicos. Madrid: Trotta.

(2004). El futuro de la naturaleza humana. Buenos Aires: Paidós. 
[2005] (2006). Entre naturalismo y religión. Barcelona: Paidós.

(2008). Ein Bewußtsein von dem, was fehlt. En M. Reder y J. Schmidt (eds.), Ein Bewußtsein von dem, was fehlt (pp. 26-36). Frankfurt: Suhrkamp.

[2001] (2009). Der demokratische Rechtstaat - eine paradoxe Verbindung widersprüchlicher Prinzipien? En J. Habermas, Philosophische Texte (Bd. 4: Politische Theorie) (pp. 154-175). Frankfurt: Suhrkamp.

(2012). Nachmetaphysisches Denken II Aufsätze und Repliken. Berlín: Suhrkamp.

Junker-Kenny, M. (2011). Habermas and Theology. Nueva York-Londres: t\&tclark.

Kant, I. [1794] (1963). El conflicto de las facultades. Buenos Aires: Losada.

Kettner, M. (2000). Welchen normativen Rahmen braucht die angewandte Ethik? En M. Kettner (ed.), Angewandte Ethik als Politikum (pp. 388-407). Frankfurt: Suhrkamp.

Kramnick, I., Moore, L. (2005). The Godless Constitution: A Moral Defense of the Secular State. Nueva York: W.W. Norton \& Company N.C.

Küng, H. (1997). Una ética mundial para la economía y la política. Madrid: Trotta. (2006). Proyecto de una ética mundial. Madrid: Trotta.

Küng, H., Kuschel, K.-J., eds. (2006). Ciencia y ética mundial. Madrid: Trotta.

Laborde, C. (2013). Political liberalism and religion: On separation and establishment. The Journal of Political Philosophy, Vol. 21, N 1, 67-86.

Lafont, C. (2009). Religion and the public sphere. What are the deliberative obligations of democratic citizenship? Philosophy \& Social Criticism, Vol. 35, Nos 1-2, 127-150.

(2013). Religious Pluralism in a Deliberative Democracy. Disponible en http://punzel. org/Relativism/LaFont-PluralismAndDemocracy.pdf [marzo 2014].

López de Lizaga, J. (2011). Verdades religiosas, política laica: Habermas sobre la religión en la esfera pública. En J. Franzé y J. Abellán (eds.), Política y verdad (pp. 175-208). Madrid: Plaza y Valdés.

Lynn, B. (2007). Piety \& Politics. The Right-Wing Assault on Religious Freedom. Nueva York: Random House.

Maliandi, R. (2006). Ética: dilemas y convergencias. Cuestiones éticas de la identidad, la globalización y la tecnología. Buenos Aires: Biblos.

McConnell, M. (1992). Accommodation in religion: An update and response to critics. George Washington Law Review 60 (3), 685-742.

McCrudden, Ch. (2012). Legal and Roman Catholic conceptions of Human Rights: Convergence, divergence and dialogue? Oxford Journal of Law and Religion, Vol. 1, No 1, 81-107.

McGraw, B. (2010). Faith in Politics. Religion and Liberal Democracy. Cambridge: Cambridge University Press.

Mendieta, E., VanAntwerpen, J. (2011). Elpoder de la religión en la esfera pública. Madrid: Trotta.

Miranda L. (2007). Secularización: doctrina, teoría y mito. Un debate desde la historia sobre un viejo tópico de la sociología. Cuadernos de Historia, $\mathrm{N}^{\circ}$ 9, 43-63. 
Peters, B. [1994] (2007). Der Sin von Öffentlichkeit. Der Sin von Öffentlichkeit. Frankfurt: Suhrkamp.

Piñeiro, E. (2010). La participación de la iglesia y los católicos en la historia de la patria: 18101940. Conferencia dictada en la Jornada de Agentes de Pastoral, Argentina, 10 de abril de 2010. Disponible en http://www.obispado-si.org.ar/asambleas/participacion_iglesia. pdf [julio 2014].

Pizzi, J. (2001). Habermas y la religión. Algunas consideraciones. Recerca. Revista de pensament $i$ anàlisi, $\mathrm{N}^{\circ} 1,53-68$.

Prono, S. (2013). Política y religión en Habermas. Análisis crítico de una problemática relación desde el concepto habermasiano de democracia deliberativa. Trabajo expuesto en el IX Coloquio Habermas, Río de Janeiro, 4-7 de junio.

Rawls, J. [1971] (1999a). A Theory of Justice. Cambridge: Harvard University Press. (1999b). The Law of Peoples with "The Idea of Public Reason Revisited". Cambridge: Harvard University Press.

(1999c), Collected Papers, Freeman S. (ed.). Cambridge: Harvard University Press. [1993] (2005). Political Liberalism. Nueva York: Columbia Univesity Press.

Reigadas, C. (2011). Modernidad, secularización y religión en el pensamiento actual de Habermas. En D. Michelini, H. Neumann Soto y R. de Miguel (eds.), Ética del discurso. Desafíos de la interculturalidad y la religión en un mundo global (pp. 279-293). Río Cuarto: Ediciones del ICALA.

Schmitt, C. [1922] (2008). Politische Theologie. Vier Kapitel zur Lehre von der Souveränität. Berlín: Duncker \& Humblot.

West, C. (2011). Prophetic religion and the future of capitalist civilization. En E. Mendieta y J. Vanantwerpen (eds.), The Power of Religion in the Public Sphere (pp. 92-101). Columbia: Columbia University Press. 